\title{
Intercomparison of Aerosol Instrumental Responses Using AEROTRAK, SMPS, and APS in a Simulated Building Environment
}

Approved for public release. Distribution is unlimited.

Mengdawn Cheng Erik Kabela

Paula R. Cable-Dunlap

January 21, 2021 


\section{DOCUMENT AVAILABILITY}

Reports produced after January 1, 1996, are generally available free via US Department of Energy (DOE) SciTech Connect.

Website www.osti.gov

Reports produced before January 1, 1996, may be purchased by members of the public from the following source:

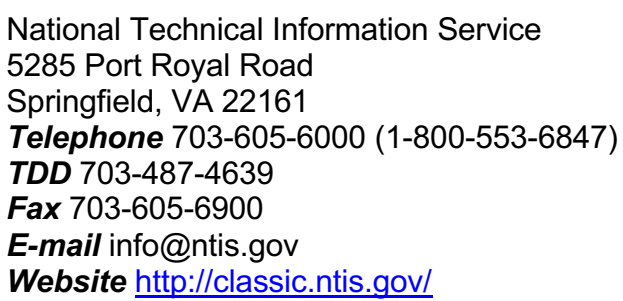

Reports are available to DOE employees, DOE contractors, Energy Technology Data Exchange representatives, and International Nuclear Information System representatives from the following source:

Office of Scientific and Technical Information

PO Box 62

Oak Ridge, TN 37831

Telephone 865-576-8401

Fax 865-576-5728

E-mail reports@osti.gov

Website http://www.osti.gov/contact.html

This report was prepared as an account of work sponsored by an agency of the United States Government. Neither the United States Government nor any agency thereof, nor any of their employees, makes any warranty, express or implied, or assumes any legal liability or responsibility for the accuracy, completeness, or usefulness of any information, apparatus, product, or process disclosed, or represents that its use would not infringe privately owned rights. Reference herein to any specific commercial product, process, or service by trade name, trademark, manufacturer, or otherwise, does not necessarily constitute or imply its endorsement, recommendation, or favoring by the United States Government or any agency thereof. The views and opinions of authors expressed herein do not necessarily state or reflect those of the United States Government or any agency thereof. 
Environmental Sciences Division

\title{
COMPARISON OF AEROSOL INSTRUMENTAL RESPONSES USING TSI AEROTRAK, SMPS, AND APS IN A SIMULATED BUILDING ENVIRONMENT
}

\author{
Mengdawn Cheng \\ Erik Kabela \\ Paula R. Cable-Dunlap
}

Date Published: January 21, 2021

Prepared by

OAK RIDGE NATIONAL LABORATORY

Oak Ridge, TN 37831-6283

managed by

UT-BATTELLE, LLC

for the

US DEPARTMENT OF ENERGY

under contract DE-AC05-00OR22725 



\section{TABLE OF CONTENTS}

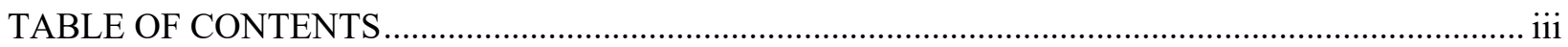

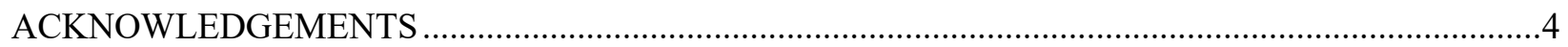

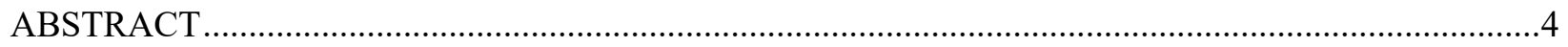

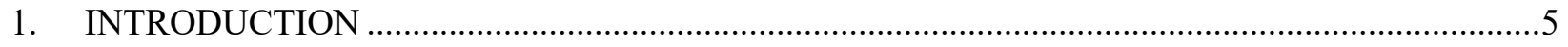

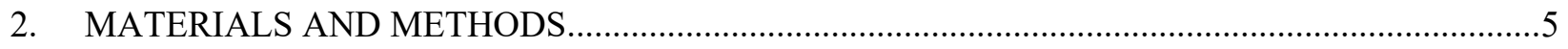

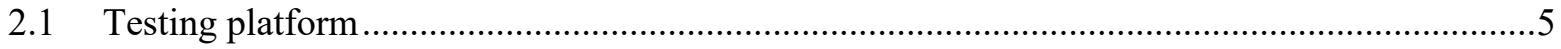

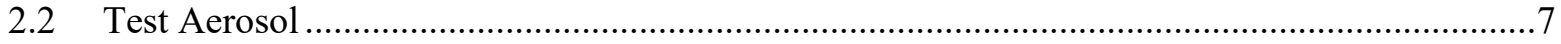

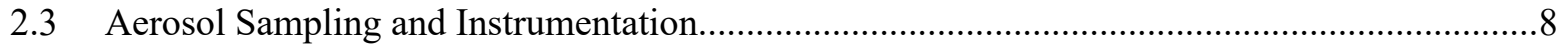

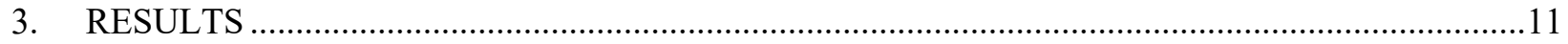

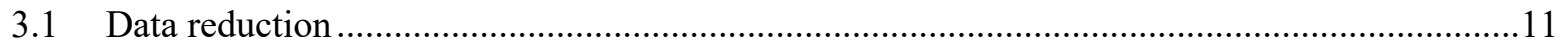

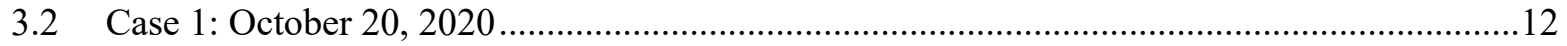

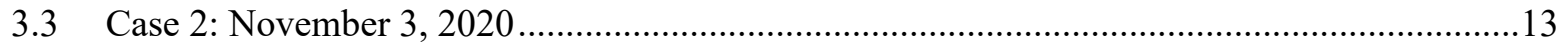

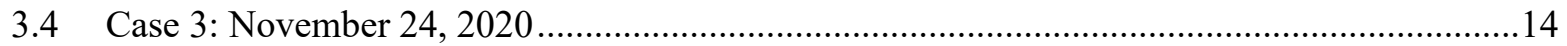

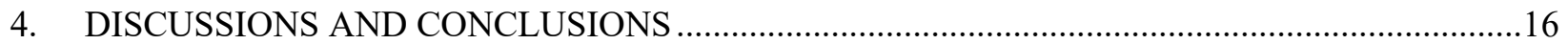

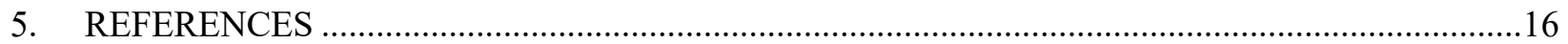




\title{
ACKNOWLEDGEMENTS
}

This work was funded by the NA-21 Program within the US Department of Energy's National Nuclear Security Administration. Sean Chien is acknowledged for providing field supports, and Kashif Nawaz and Piljae Im administered the Flexible Research Platform for the study.

\begin{abstract}
In this work, three aerosol instruments were intercompared by using data collected from field campaigns in a simulated building environment during the last quarter of 2020 from October to December at Oak Ridge National Laboratory. The three aerosol instruments-AeroTrak Model 9110, Scanning Mobility Particle Spectrometer (SMPS) 3080L + 3025A, and Aerodynamic Particle Sizer (APS) 3320-were manufactured by TSI Inc. to perform in situ measurements of particle number concentration in the air. These instruments were co-located in one room in which an aerosol generator was used to produce a defined aerosol population for the instruments to sample and detect in each campaign. The SMPS measured aerosol particles with diameters from 0.01 to $0.7 \mu \mathrm{m}$, APS measured aerosol particles with diameters from 0.5 to $20 \mu \mathrm{m}$, and AeroTrak measured aerosol particles with diameters from 0.1 to $10 \mu \mathrm{m}$. The results suggest that although AeroTrak is fast and easy to use, it does not provide measurements comparable with those obtained by SMPS and APS. The differences in particle counts were orders of magnitude in size (i.e., the AeroTrak data were unreasonably small in the tested scenarios). The results clearly indicate that AeroTrak should not be used in ambient applications in which the level of particle concentration is expected to be high. This would cause difficulty to a campaign in which the dilution factor is unknow a priori. The high particle concentration could also lead to an erroneous aerosol size distribution (e.g., a bimodal size distribution was measured as opposed to a single-mode one). The number concentration limit that AeroTrak is expected to run reliably (i.e., with a counting coincidence error less than $\pm 10 \%$ ) is approximately three to four per cubic centimeter. This suggests that the instrument is best used in a clean room environment, not in an ambient or indoor application, such as the Flexible Research Platform campaigns.
\end{abstract}




\section{INTRODUCTION}

Industrial-grade aerosol instruments are manufactured to meet custom demands and are generally designed with user-friendliness in mind. TSI Inc. was established in 1976 and for the last 50 years has been well-known for its the PortaCount Respirator Fit Tester for military applications and a suite of aerosol instruments. Among the aerosol instruments are the industry de facto Scanning Mobility Particle Spectrometer (SMPS) and Aerodynamic Particle Sizer (APS), which enable the real-time size measurement of aerosol particles from $0.01 \mu \mathrm{m}$ to tens of micrometers when data from both instruments are combined.

Oak Ridge National Laboratory (ORNL) purchased an AeroTrak (TSI Model 9110) unit in FY20 for advanced field measurement operations. AeroTrak is an optical particle counter (OPC) designed to detect the optical diameter (OD) aerosol in the $0.1-10.0 \mu \mathrm{m}$ range resolved in eight size bins in real time according to TSI Inc. SMPS (TSI Model 3936L) has high resolution (64 bins) and can size aerosol particles in the electrical mobility diameter (EMD) 0.01-0.7 $\mu \mathrm{m}$ range. APS (TSI Model 3320) can size the aerodynamic diameter (AD) aerosol from 0.5 to $20 \mu \mathrm{m}$ into 51 bins. In theory, the pair or combination of SMPS and APS can provide aerosol particle size measurement from 0.01 to $20 \mu \mathrm{m}$ - an impressive five orders of magnitude.

The goal of this work was to evaluate AeroTrak performance against other available aerosol instruments, such as SMPS and APS, in a range of field conditions. ORNL is conducting an ongoing study for the US Department of Energy Efficiency and Renewable Energy Building Technology Office to investigate the transmission of aerosol particles with diameters from 0.1 to $10 \mu \mathrm{m}$ in an office building during the first quarter of FY21. The study will provide an opportunity to evaluate AeroTrak. This report summarizes the size measurement data and discusses the finding from the study.

\section{MATERIALS AND METHODS}

\subsection{TESTING PLATFORM}

The ORNL Building Technology Program operates a Flexible Research Platform (FRP) in Oak Ridge, Tennessee (Figure 1). The campaign experimental setup is shown in Figure 2. The FRP was designed to mimic a two-story office building with large windows and a central HVAC system for the building platform. A second HVAC system can decentralize ventilation for single room experiments, if required. The platform was a good choice for studying the aerosol transmission in an office building setting because the FRP has been used in previous indoor air quality studies; thus, the infrastructure and personnel experience exist to support the aerosol transmission study. 


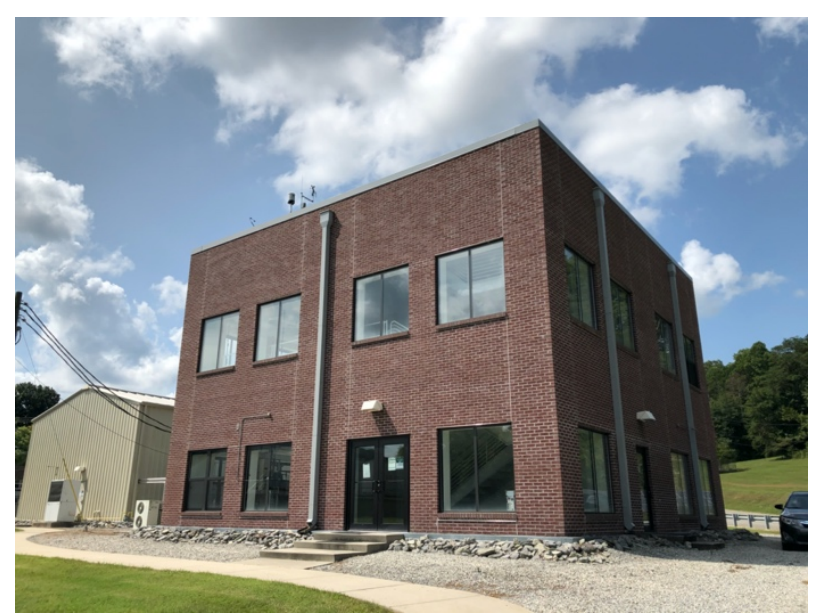

Figure 1. The ORNL FRP building on Bethel Valley Road. It is a two-story office building with five rooms on each floor. Meteorological monitoring is installed on the roof on which a MERV 7/8 filter pack is installed to provide central air.

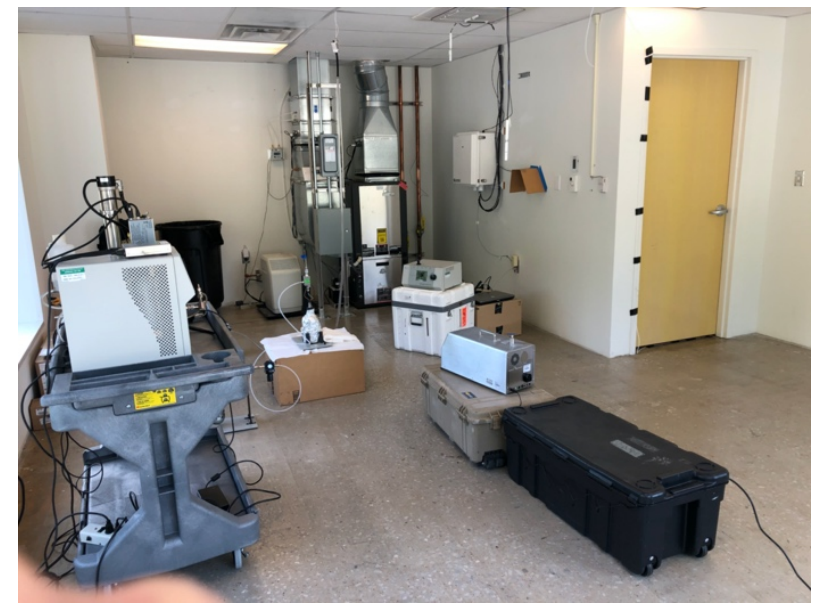

Figure 2. Experimental setup in Room 104. (Left) the SMPS on the cart, (center) aerosol generator, (far right) APS on the white box, and AeroTrak, followed by a black container.

The datasets used in this intercomparison were taken from multiple campaigns conducted in the FRP. The positions of aerosol generation, aerosol instruments, and cascade samplers are shown in Figure 3. There were five connected rooms: Room 102, 103, 104, 105, and 106 (designated as R102, R103, R104, R105, and R106). All five rooms were located on the first floor of the FRP. The aerosol particles generated in one room were expected to be transmitted to the other rooms through self-diffusion and building ventilation air movement. 


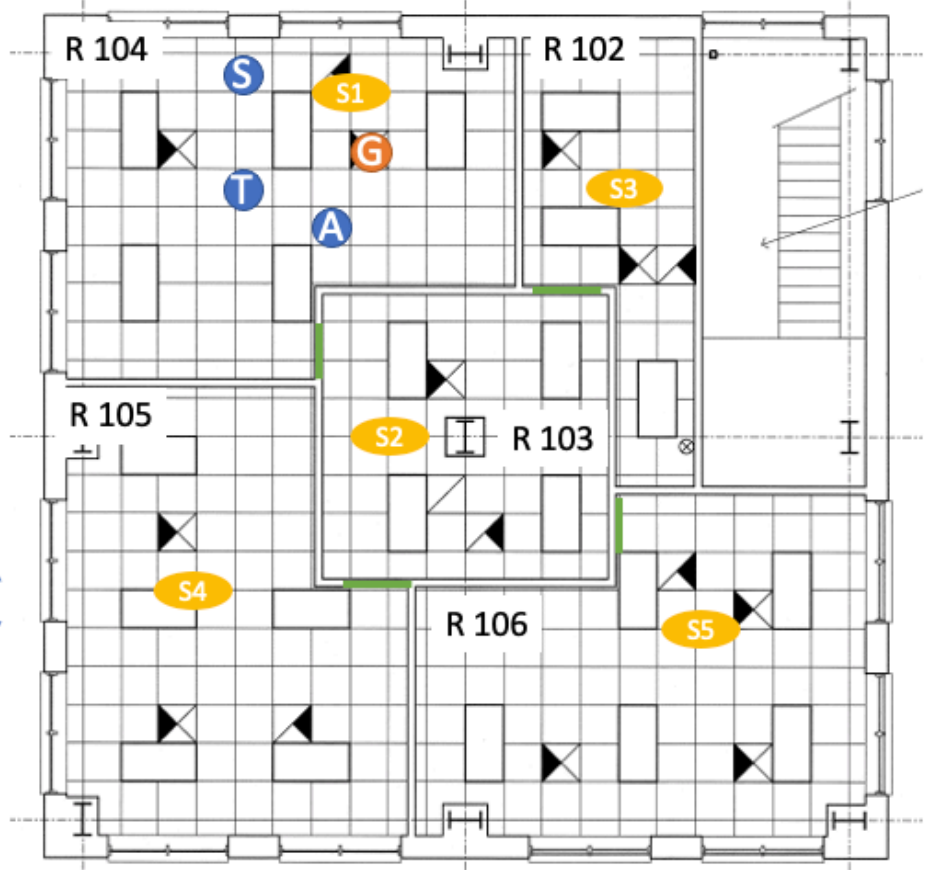

Figure 3. Display of equipment locations on the first floor. Each grid box is $2 \times 2 \mathrm{ft}$. The right-facing black triangles indicate return air (downward air flow), and the left-facing black arrows show intake. a white "S" followed by a number on the orange-yellow background stands for the SKC cascade impactors, ${ }^{1}$ and the white "G" in the orange circle in R104 stands for the aerosol generator. The white " $S$ " in the blue circle shows where the SMPS was located. The white "A" in the blue circle shows the APS location. The white "T" in the blue circle shows the location of AeroTrak in R104.

Room temperature and relative humidity $(\mathrm{RH})$ have some impacts on the aerosol particles and thus the transmission. For example, a lower RH tends to dry the aerosol and reduce the particle size if the aerosol particle is hygroscopic. During the experiments, no one could enter the building, minimizing - if not eliminating - potential interruption.

In Figure 3, the black right-facing triangles are the ventilation air returns, and the black left-facing triangles are the ventilation intakes. The rooms are interconnected but are practically separated by a wall; the green bars show the location of the entrance doors for each room. The nominal ventilation flow rate for each room was approximately $320 \mathrm{CFM}$ or seven air exchanges per hour, which can be varied. The $\mathrm{RH}$ in the room was $\sim 20-50 \%$, and temperature was maintained at $\sim 70^{\circ} \mathrm{F}$. The building air distributed by the HVAC system communicates the airflow among the rooms through the plenum on the ceiling.

Scenarios of building operation — such as doors fully open, doors closed, and different ventilations - were designed before an experiment or campaign. The design details are unimportant to this study because this study focuses on instrumental intercomparison. The description of the experimental setup and facility preparation are provided for report completeness only. All three instruments were positioned in the same room (R104), and only the aerosol instrument response data taken were used in the intercomparison.

\subsection{TEST AEROSOL}

To minimize operational and environmental, safety, and health concerns, sodium chloride $(\mathrm{NaCl})(\mathrm{MW}=$ $58.44 \mathrm{~g} \mathrm{~mol}^{-1}$; CAS \#: 7647-14-5; Sigma Aldrich) was selected as the material for testing the aerosol.

${ }^{1}$ https://www.skcinc.com/products/sioutas-five-stage-cascade-impactor 
Fluorescein $\left(\mathrm{C}_{2} \mathrm{H}_{12} \mathrm{O}_{5}\right)\left(\mathrm{MW}=332.31 \mathrm{~g} \mathrm{~mol}^{-1}\right.$; CAS \#: 2321-07-5; Sigma Aldrich $)$ was added to the aerosol particles to provide a fluorescent signal for enhanced aerosol characterization and positive identification of the generated particles to discriminate against the background indoor particles in FRP that could be in the same size range but have no fluorescent signal. Various solute concentrations were prepared and used in aerosol generation to produce aerosol in different size distributions and concentration levels. TSI Model 3074, a constant aerosol atomizer, was used for the particle generation displayed in Figure 2. An alternative generator, the BGI nebulizer, was also used in one campaign to produce different aerosol populations based on the same chemical ingredients in the third campaign in this report.

Aerosol particles collected at the five stages of an SKC impactor were extracted after each campaign and dissolved in a cuvette for fluorescent analysis. The recovery was near $100 \%$ in a separate study. The fluorescent signal of aerosol particles was detected by a custom-made fiber-optics coupled spectrometer with an LED excitation wavelength of $470 \mathrm{~nm}$, and the fluorescent emission was detected at $525 \mathrm{~nm}$ with a high-resolution spectrometer (OceanInsight Model HR4000CG-UV-NIR). The spectral signal was recorded and processed by the OceanView software on a 64 bit Windows-based laptop. The absolute minimum detection level by this spectral system was determined before the campaigns to be approximately $300 \mathrm{ng}$ or $0.3 \mu \mathrm{g}$, which was sufficient for the intended study. Again, this fluorescent signal was not part of the aerosol instrumentation intercomparison study and is not reported in this document. The brief description of the fluorescence setup and detected signals are for the completion of this report.

\subsection{AEROSOL SAMPLING AND INSTRUMENTATION}

AeroTrak (TSI Model 9110-01) is an OPC designed to detect OD aerosol in the 0.1-10.0 $\mu \mathrm{m}$ range resolved in eight sizes of bins in real time according to TSI Inc. Figure 4 shows a photo of the dilution devices for AeroTrak, and Figure 5 shows the AeroTrak portable instrument. The size channels are 0.1, $0.15,0.2,0.25,0.3,0.5,1.0$, and $5.0 \mu \mathrm{m}$. AeroTrak was used to measure indoor aerosol at FRP with a 15 min sampling time. The instrument sampled with a flow rate of 1 CFM or 28.3 liters per minute (LPM) and was operated with an alternating current power source during the campaigns, although AeroTrak could also be operated by $24 \mathrm{~V}$ of direct current power source.

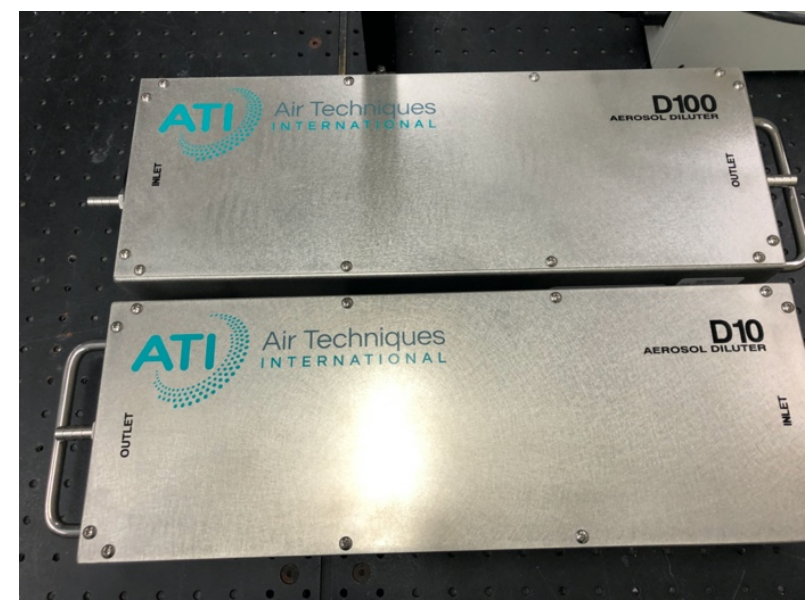

Figure 4. Diluters for use with AeroTrak. 


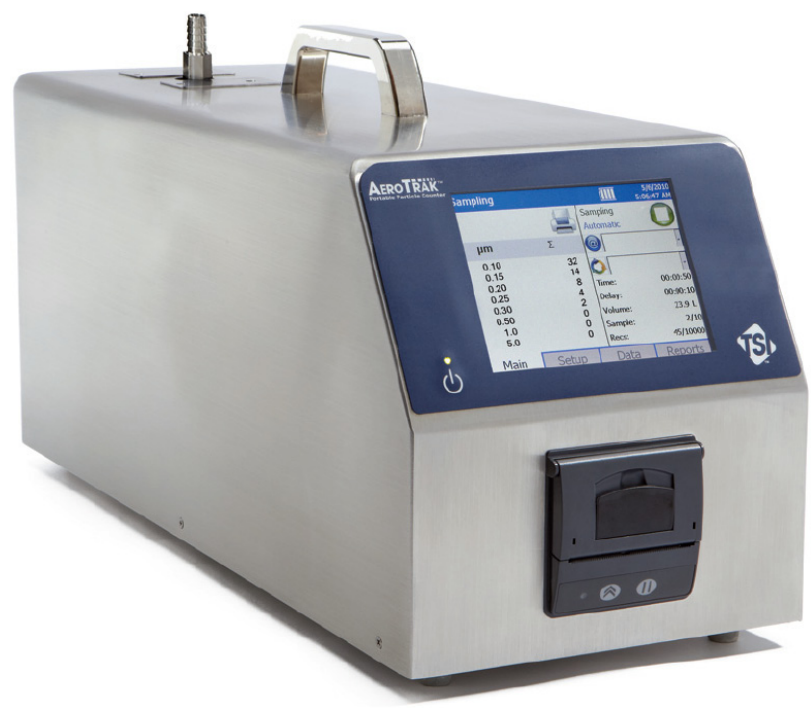

Figure 5. TSI 9110-01 AeroTrak Portable Airborne Particle Counter.

SMPS (TSI Model 3080L + 3025A) consists of an electrostatic classifier that operates based on the theory of electrophoresis to measure aerosol size (Knutson and Whitby 1975) and an ultrafine condensation particle counter (UCPC) (TSI Model 3025A). Figure 6 shows a photo of the SMPS system equipped with a long Differential Mobility Analyzer (DMA) (TSI Model 3081) as the classifier. A soft x-ray (9.4 kV) was used to neutralize charges to the Boltzmann distribution. A flow rate of 10:1 was used for the DMA. The instrument was operated at a high-resolution (64 channels) mode capable of 15 min sizing aerosol particles in the EMD 0.01-0.7 $\mu \mathrm{m}$ range. A sample time was increased for each size channel with larger sizes to improve Poisson counting statistics. The raw DMA data were inverted with a charge correction to correct the mobility size distribution for multiple charged particles. The TSI software AIM V9.0 was used to reduce the DMA data with those of UCPC to yield an EMD size distribution.

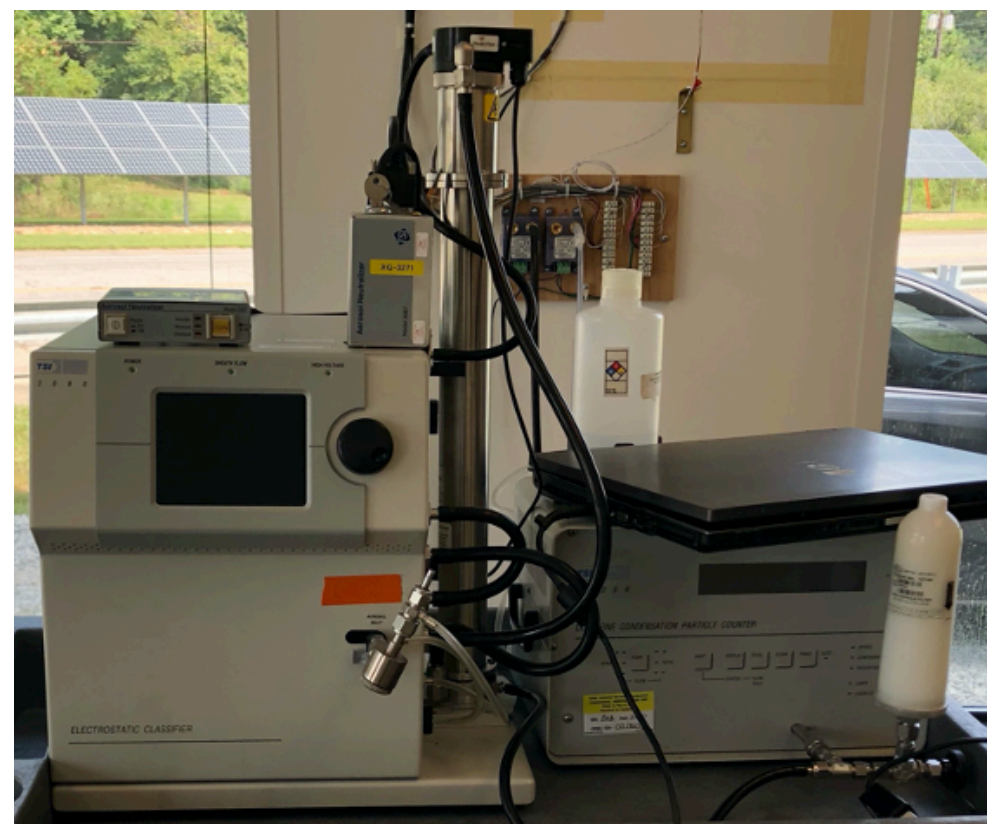

Figure 6. SMPS system equipped with a long DMA (TSI Model 3081) as the classifier. 
The APS (TSI Model 3320) is a time-of-flight instrument that measures the aerosol of AD from 0.5 to $20 \mu \mathrm{m}$ into 52 channels. Figure 7 shows a picture of the APS 3320. The APS operates at a 5 LPM sampling flow rate. One LPM was used as an aerosol sample, and the remaining 4 LPM were filtered and used internally as the sheath air flow. The APS sample time was also set to be $15 \mathrm{~min}$, which was consistent with that of the other two instruments.

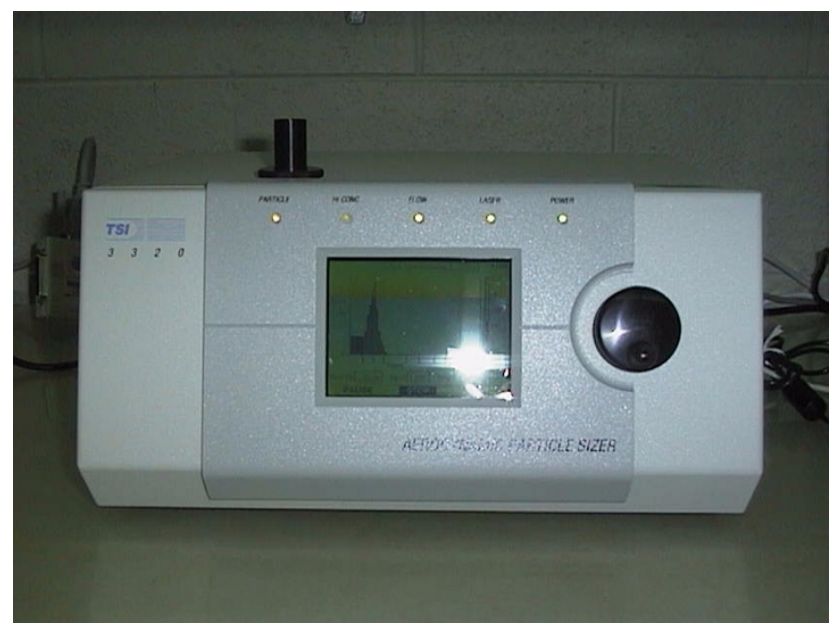

Figure 7. TSI 3320 APS.

In theory, the pair or combination of SMPS and APS can provide aerosol particle size measurement from 10 to $20,000 \mathrm{~nm}$, or 0.01 to $20 \mu \mathrm{m}$ (e.g., all three instruments sampled independently from the indoor air, not from the same inlet manifold). Thus, the aerosol might be sampled from different air parcels if the concentration distribution indoors is not uniform. In separate analyses of the indoor air samples, the 3D distribution of aerosol concentration in Room 14 was relatively uniform with a variation of approximately $\pm 10 \%$. Also, the aerosol particles sampled into each instrument were not preconditioned (e.g., dried or heated to a consistent RH or temperature). These sample inconsistencies might also contribute to data variation, although these inconsistencies were not quantified in this study. However, sampling independently from the indoor room air also eliminates any possible particle losses that might result from sampling from the same manifold and from sample conditioning.

Few published data regarding the performance of AeroTrak exist, and much less was the intercomparison of this instrument to other aerosol instruments. A cautionary note for performing intercomparisons of instrumental responses is that the OD, EMD, and AD derived from AeroTrak, SMPS, and APS measurement data, respectively, are calculated as a diameter "equivalent" to a sphere that has the same physical modality. For instance, an $\mathrm{AD}$ is used to estimate the "sphere-equivalent" diameter $D_{p}$ of a nonspherical particle of density $\rho_{\mathrm{p}}$ and shape factor $\chi_{\mathrm{p}}$ that has the same settling velocity (i.e., aerodynamic property) as a spherical particle of diameter $D_{a}$ and density 1 . The relationship between $D_{a}$ and $D_{p}$ is as follows:

$$
D_{p}=D_{a} \sqrt{\left[\frac{C_{a}}{\rho_{e} C_{p}}\right\rceil}
$$

where $C_{a}$ and $C_{p}$ are the Cunningham correction factor for the particle and the aerodynamic particle. The effective density $\rho_{e}$ is defined as $\frac{\rho_{p}}{\chi_{p}}$. Strictly speaking, an OD of $1 \mu \mathrm{m}$ is not identical to an AD of $1 \mu \mathrm{m}$; similarly, an EMD of $0.3 \mu \mathrm{m}$ is different from an OD of $0.3 \mu \mathrm{m}$ without knowing the aerosol particles in 
question. There are derived relationships among these diameters if the property of the aerosol in question is known and some assumptions are made. Section 3 shows such a relationship between AD and EMD.

TSI calibrated AeroTrak by using particles of known size and physical, chemical, and/or optical properties, such as polystyrene latex spheres (PSL). Aerosol properties could vary in an environment due to the environmental conditions (e.g., temperature, $\mathrm{RH}$, or existing gas and particulate materials). These properties do not reflect those of laboratory aerosols used for manufacture's calibration purposes. Many previous studies showed that significant underestimation in volume concentrations were derived from OPC measurements when no corrections for the particle in situ optical properties were applied (Pinnick et al. 2000, Kim 1995, Hering and McMurry 1991). Also, the size channels obtained from PSL calibration could be different from those calibrated with other types of aerosols by $10 \%$ or more (Hand and Kreidenweis 2002).

\section{RESULTS}

The three aerosol instruments - SMPS, APS, and AeroTrak - were co-located with the aerosol generator in R104; Figure 3 provides the relative locations of these devices. The generator (TSI Model 3074) continuously generated test aerosol, and the air concentrations of the aerosol particles were each taken by the three aerosol instruments at a 15 min interval. Sixteen instrumental curves were generated in a $4 \mathrm{~h}$ experiment by an instrument. Particle number concentrations (in cubic centimeters) obtained by each instrument were averaged based on the 16 curves as a function of the equivalent particle size. The variation of the number concentrations over the period of $4 \mathrm{~h}$ for an instrument was calculated as a standard deviation and plotted as an error bar for each size bin or channel. The size range that the authors want to use is 0.1 to $10 \mu \mathrm{m}$, which is primarily the size range that AeroTrak is designed to detect.

\subsection{DATA REDUCTION}

The EMD and AD data were combined to generate a continuous size distribution function from 0.01 to $20 \mu \mathrm{m}$ based on the relationship derived by Peters et al. (1993). The authors converted EMD into volume equivalent diameter (VED), which requires the calculation of the Cunningham slip correction factor. The calculation also requires the dynamic shape factor of the aerosol particles. Because the dynamic shape factor for $\mathrm{NaCl}$ particles is 1.08 near 1.0, the MED is assumed to be VED. The VED is converted into AD for $\mathrm{NaCl}$ particles by using the following relationship:

$$
\sqrt{C_{A D}} A D=\sqrt{\frac{C_{V E D} \rho_{p}}{\chi \rho_{o}}} V E D
$$

where $C_{A D}$ and $C_{V E D}$ are the Cunningham slip correction factors for $\mathrm{AD}$ and VED, respectively, for $\mathrm{NaCl}$ particles. $\chi$ is the dynamic shape factor, $\rho_{\mathrm{o}}$ is $1 \mathrm{~g} \mathrm{~cm}^{-3}$, and $\rho_{p}$ is the $\mathrm{NaCl}$ particle density of $2.16 \mathrm{~g} \mathrm{~cm}^{-3}$.

This procedure allows the SMPS and APS to be combined to form one size distribution from $10 \mathrm{~nm}$ to 20 $\mu \mathrm{m}$. This operation eliminates the first five APS data points below $0.77 \mu \mathrm{m}$ and adds the APS data points beyond $0.77 \mu \mathrm{m}$ to the SMPS data to make a continuous size distribution from 0.01 to $20 \mu \mathrm{m}$. For each campaign, the SMPS and APS size distribution is shown. Then, a plot is displayed that compares the combined SMPS + APS curve and AeroTrak curve for the number concentration range at which both curves are legible. 


\subsection{CASE 1: OCTOBER 20, 2020}

Figure 8 shows a plot of the averaged number concentrations in cubic centimeters measured by SMPS and APS for the experiment on October 20, 2020. The error bars show the data fluctuation over time. The fluctuation of the SMPS data is large for particle sizes smaller than $\sim 70 \mathrm{~nm}$. The evaporation and condensation processes occur at the millisecond timescale. Because small particles are more sensitive to temperature and $\mathrm{RH}$ in a micro room air parcels than in larger room air parcels, the temporal fluctuation of the number concentration for smaller particles was expected to be higher.

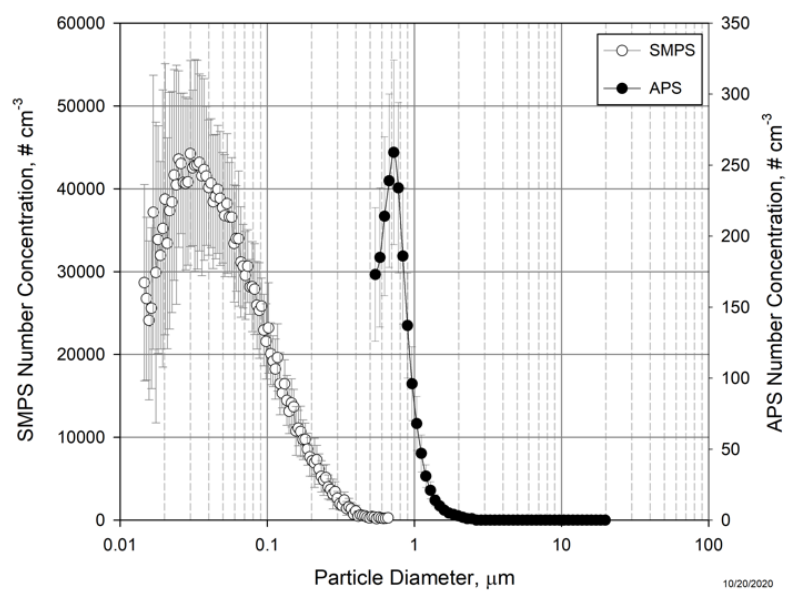

Figure 8. Plot of SMPS and APS data for the Case 1 campaign.

The three datasets are plotted with two individual $y$-axes because the particle concentrations in the datasets have a large numeric range. The averaged SMPS and APS data are plotted in Figure 8 to show particle distributions from 0.01 to $20 \mu \mathrm{m}$. The combined SMPS + APS data were plotted in Figure 9 with the combined curve concentration above 10,000 excluded because these datasets were as large as 2-4 orders of magnitude. The large size range and difference in the number concentration further emphasizes the importance of using multiple aerosol instruments in a campaign. No single aerosol instrument is currently capable of 0.01 to $20 \mu \mathrm{m}$ measurements.

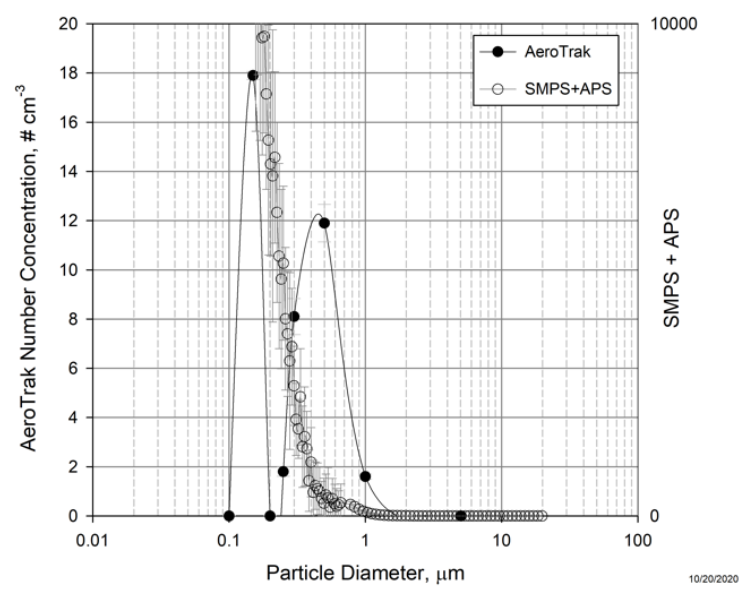

Figure 9. Plot of combined SMPS + APS and AeroTrak data for Case 1. Concentrations above $10,000 \mathrm{~cm}^{-3}$ were ignored. 
The AeroTrak resolution is much lower than that of SMPS or APS, as described previously. As shown in Figure 9, the number concentrations above $10,000 \mathrm{~cm}^{-3}$ were ignored to visually enhance the intercomparison. The authors also spline-plotted the data for an easier comparison. Although SMPS and APS were far apart in the room, the measurements reasonably matched in the overlapping size range from 0.5 to $0.7 \mu \mathrm{m}$, implying that the spatial fluctuation of particle concentration in R104 might be minute. Combining the SMPS + APS number concentration curves exponentially decrease the curves as the particle size increases, as shown in in Figure 9. However, the AeroTrak size distribution pattern appears bimodal in the $0.1-1 \mu \mathrm{m}$ range, which is inconsistent with that of the single-mode distribution shown by the combined SMPS + APS data. This is the first indication that the AeroTrak instrument might have been saturated by the generated aerosol concentration in the room during this experiment, causing the counting coincidence error. AeroTrak significantly underestimated the number concentrations at any particle size from 0.1 to $5 \mu \mathrm{m}$ compared with the combined SMPS + APS data, also supporting the possibility of coincidence counting error. Adding dilution for AeroTrak was recommended after this campaign. The need for dilution determined after one campaign is troublesome because this means that the AeroTrak is not a strong candidate for a field campaign in ambient sampling applications.

\subsection{CASE 2: NOVEMBER 3, 2020}

The test condition in Case 2 was different from that of Case 1. Five rooms were used simultaneously for this case compared with Case 1, which only used one room. The aerosol population generated was identical to that produced for Case 1 in which an ultrafine $\left(D_{p} \leq 0.1 \mu \mathrm{m}\right)$ fraction dominates in Figure 10. The ultrafine fraction has a peak at approximately $0.04 \mu \mathrm{m}$, as recorded by SMPS. A population with a peak near $0.7 \mu \mathrm{m}$ was observed, and it was much smaller than the population observed by APS in Figure 10. Two modes differ by at least three orders of magnitude in the number concentration.

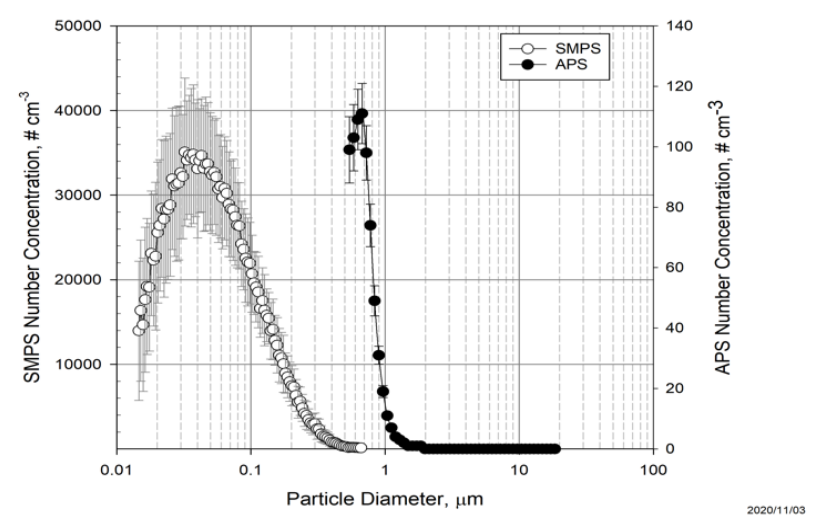

Figure 10. Plot of all SMPS and APS data for Case 2.

The total concentration levels shown in Figure 10 were lower than those in Figure 8; however, this was because the "effective" room size was increased from one to five rooms. The combined SMPS and APS data are plotted alongside AeroTrak data in Figure 11. The pattern of the AeroTrak curve matches reasonably well with that of SMPS and APS combined for this case, and both curves show smooth decreasing particle concentrations as the particle size increases. The AeroTrak number concentration was nevertheless one order of magnitude (i.e., 10 times) smaller than that of SMPS and APS combined for particle size in the $0.1-1.0 \mu \mathrm{m}$ range. The last data point at $5 \mu \mathrm{m}$ was zero concentration. The authors think that this 10 times smaller difference was likely caused by the material property, as discussed previously, instead of by the counting coincidence error. This is because two diluters $(10 \times$ and $100 \times)$ 
were used in series during the sampling to create a dilution factor of 1,000 that could have effectively reduced the coincidence error observed in the first campaign. This level of dilution was large but appears to have provided the AeroTrak with the correct level of aerosol particle counts. Otherwise, the AeroTrak curve, as shown in Figure 11, would not match the curve of the combined SMPS + APS. A multimodal curve like the one in Figure 10 could have occurred if the optical detector were saturated.

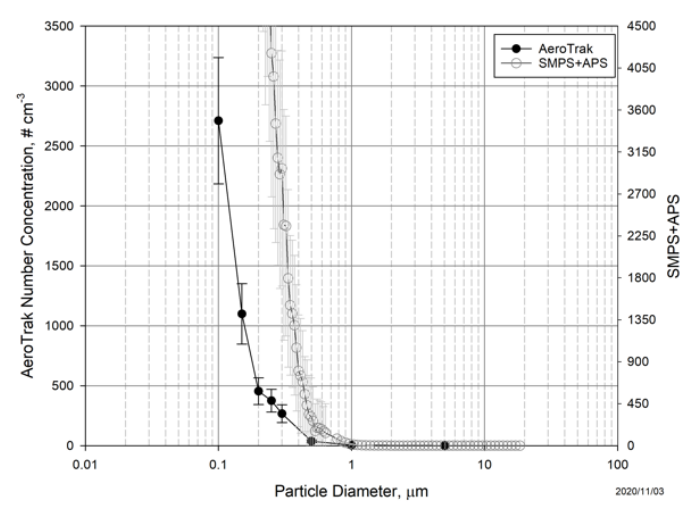

Figure 11. Plot of combined SMPS + APS and AeroTrak data for Case 2. SMPS + APS concentrations $\geq 4,000 \mathrm{~cm}^{-3}$ were not plotted.

The results from Cases 1 and 2, are summarized as follows.

1. AeroTrak is not designed for FRP applications, primarily because the concentration of particles in that environment was higher than the AeroTrak saturation level. Thus, dilution is required for proper use in an ambient campaign in which a significant counting coincidence error could occur due to the high particle concentration.

2. AeroTrak should not be used without the recommended dilution because the coincidence error could lead to an erroneous aerosol size distribution with multiple modes, as observed in the first campaign, when in reality the distribution has only one mode (or one peak size).

3. AeroTrak operates without a dilution configuration and significantly underestimated the number concentration from that obtained by SMPS + APS. This suggests that the instrument should not be used for quantitative measurement.

\subsection{CASE 3: NOVEMBER 24, 2020}

AeroTrak was tested again in the third campaign on November 24, 2020. This is also a one-room (R104) experiment in which aerosol particles were generated by a BGI nebulizer different from TSI 3074 . The BGI nebulizer has three jets, and the TSI generator has only one jet. The BGI nebulizer was operated at a lower pressure, which enabled larger than $1 \mu \mathrm{m}$ particles to be generated in a higher concentration. The aerosol size distributions observed by SMPS and APS before combination are shown in Figure 12. 


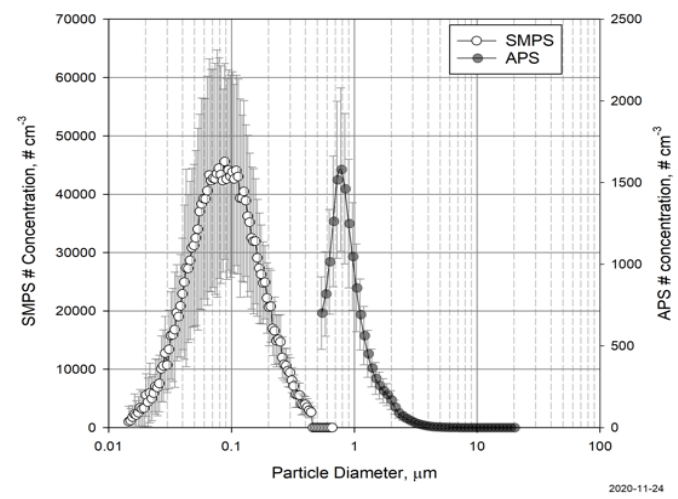

Figure 12. Plot of all SMPS and APS data for Case 3.

The particle population was designed to contain a bimodal number distribution in this campaign in which the ultrafine population peaked near $0.08 \mu \mathrm{m}$, as recorded by SMPS, whereas the other population with a larger particle size peaked at $0.85 \mu \mathrm{m}$, as recorded by APS. Note that $0.85 \mu \mathrm{m}$ by particle number is similar to $3 \mu \mathrm{m}$ by mass in an aerosol size distribution for $\mathrm{NaCl}$ particles. Also, the number concentration for the larger size fraction was at least 10 times higher than those recorded in the last two campaigns, but the ultrafine fraction was approximately identical to that of the last two experiments.

A $100 \times$ dilutor was used for the AeroTrak measurement in Case 3. As shown in Figure 13, the instrumental reading of AeroTrak was low by two or three orders of magnitude compared with that of SMPS + APS during this campaign. This result is also consistent with that of the first case, clearly indicating that the AeroTrak was affected by the higher concentration and use of an incorrect dilution. The overall pattern of the AeroTrak size distribution did not match that of the combined SMPS + APS in the $0.1-1.0 \mu \mathrm{m}$ range. A peak was found at $0.3 \mu \mathrm{m}$ OD, which was not observed in the combined SMPS + APS curve and was likely an optical detection error. This pattern is consistent with that observed in the first case.

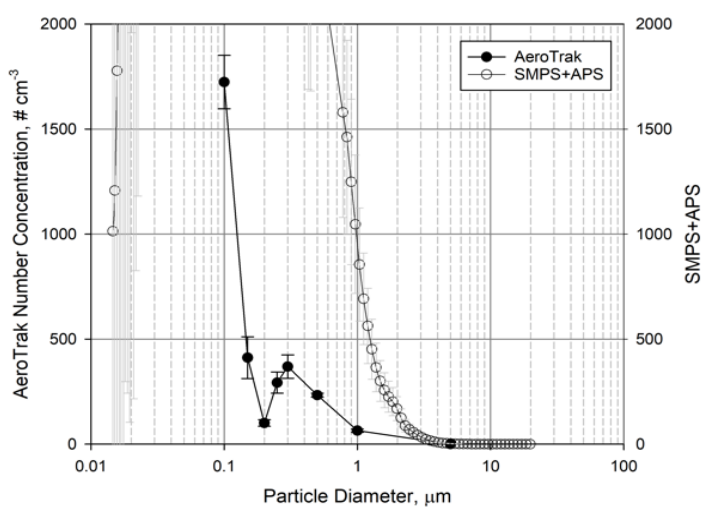

Figure 13. Plot of SMPS + APS and AeroTrak data for Case 3. SMPS + APS data were not plotted for concentrations $\geq 2,000 \mathrm{~cm}^{-3}$ 
The third dataset clearly indicated that AeroTrak cannot provide reliable particle counting in an ambient environment. The Case 3 results also indicated that 100× dilution was insufficient for AeroTrak in the FRP campaign and that a $1,000 \times$ dilution is required.

\section{DISCUSSIONS AND CONCLUSIONS}

The maximum concentration level of aerosol particles that AeroTrak can count within $\pm 10 \%$ of the coincidence error is approximately $3-4 \mathrm{~cm}^{-3}$ of air (basically a clean room), whereas the APS is $10^{3} \mathrm{~cm}^{-3}$ and the condensation particle counter (CPC) is $10^{5} \mathrm{~cm}^{-3}$. Sample dilution is required for AeroTrak in the FRP campaigns. The particle number concentration of the supermicron-sized aerosol was not high enough in the campaigns to cause the coincidence error in APS detection, so it did not require a dilution sampling. On the other hand, SMPS has the classifier to size particles upfront, so the number concentration to be detected at each of the 64 size channels by CPC would not exceed its saturation level. SMPS also does not require dilution sampling. The results from these three campaigns suggest that AeroTrak should not be applied for a quantitative measurement in an ambient environment if the dilution factor is unknown. The results obtained in these three campaigns clearly indicate that the AeroTrak should not be used in ambient applications in which the level of particle concentration is expected to be high. A baseline concentration in an ambient or indoor environment would be at $10^{2}$ to $10^{3} \mathrm{~cm}^{-3}$, suggesting that $1,000 \times$ dilution is a minimal requirement for using AeroTrak.

\section{REFERENCES}

Hering, S.V., and McMurry, P.H. (1991). Optical Counter Response to Monodisperse Atmospheric Aerosols, Atmos. Environ. 25A:463-468.

Hand, J. L. \& Kreidenweis, S.M. (2002) A New Method for Retrieving Particle Refractive Index and Effective Density from Aerosol Size Distribution Data, Aerosol Sci. Technol., 36:10, 1012-1026, DOI: $10.1080 / 02786820290092276$

Kim, Y.J. (1995). Response of the Active Scattering Aerosol Spectrometer Probe (ASASP-100X) to Different Chemical Composition, Aerosol Sci. Technol. 22:33-42.

Knutson, E. O., and Whitby, K. T. (1975). Aerosol Classification by Electric Mobility: Apparatus, Theory and Applications, J. Aerosol Sci. 6:443-451.

Peters, T.M., Chien, H.M., Lundgren, D.A. and Keady, P.B. (1993) Comparison and Combination of Aerosol Size Distributions Measured with a Low Pressure Impactor, Differential Mobility Particle Sizer, Electrical Aerosol Analyzer, and Aerodynamic Particle Sizer, Aerosol Sci. Technol., 19(3): 396-405, DOI: 10.1080/02786829308959647

Pinnick, R.G., Pendleton, J.D., and Videen, G. (2000) Response Characteristics of the Particle Measuring Systems Active Scattering Aerosol Spectrometer Probes, Aerosol Sci. Technol. 33:334-352. 